\title{
Two Preservice Training Approaches
}

Baker

University

of Michigan

In an attempt to institute and evaluate a form of multicultural training for teachers, the author conducted a research project in 1971 . This project was designed to determine whether changes could be made in the perceptions of ethnic groups held by students enrolled in an elementary school methods course emphasizing a multiethnic approach to teaching (1). The study was based upon the assumption that if teachers perceived ethnic groups favorably, they were more likely to develop the skills for teaching a multicultural curriculum (2). The findings of this study indicated that multiethnic training can alter students' perceptions of ethnic groups.

The study's conclusion provided the support for additional research designed to measure the effect of multicultural training on student teachers. This training utilized a workshop approach for preservice teachers in training at the University of Michigan in fall 1972. The findings were reported in the 1973 winter issue of the Journal of Teacher Education. The summary of results are as follows:

\begin{abstract}
The study was designed to determine changes in the perception of ethnic groups held by student teachers participating in a workshop on multicultural education. The hypothesis tested was: The perceptions of ethnic groups held by the students enrolled in the multicultural workshop would be altered.

The data did establish significant differences between the pre- and post-testing in the perceptions of ethnic groups held by students on both the proirrational and anti-irrational scales. The workshop involved several aspects of training, and it is difficult to determine specifically which aspects-the lectures, films, discussions, classroom experiences, or personal contacts-contributed most to the change.

The findings of this study and the previous research by the author support the belief that perceptions can be altered through training. It is, therefore, appropriate and necessary for teacher training institutions to assume this responsibility. Colleges and universities have a responsibility to provide learning experiences for teachers in training that will be consistent with the objectives of multicultural education (3)
\end{abstract}

During 1973-74 at this same university, a more comprehensive approach to multicultural training for preservice teachers was developed. Based upon a multicultural model for training teachers, the new approach involved the following stages: Acquisition, Development, and Involvement (4).

The Acquisition stage was designed to expose the preservice teachers to an analysis and evaluation of the student's own ethnic and/or cultural background, as well as to the significance of the ethnic/cultural backgrounds of others. Stage two, Development, allowed the teacher in training to develop: (1) a philosophy supportive of diversity, and (2) a rationale for teaching consistent with the conceptual framework inherent in multicultural education. The final state, Involvement, was seen as the culmination; this stage would prepare the student in training for the implementation aspects of ethnic/cultural instruction in the classroom. The involvement process included the development of teaching skills that would facilitate the teaching/learning process. In this process, both student and teacher would be expected to learn content and to interact in ways compatible with cultural diversity.

This training program required each student to elect from a prescribed course list three multicultural courses prior to their directed teaching experiences; course offerings were included from colleges and schools throughout the university. Students were free to select courses they felt were best suited for them, but were encouraged to select courses from more than one area or discipline so as to provide them with a broader range of knowledge and experience. Students were given one year (the 1973-74 academic year) to make the transition and to satisfy the course requirement.

In addition, Michigan began to integrate education courses with multicultural concepts. Stages one and two were to be satisfied by the course election requirement. Stage three was the responsibility of the teacher training institution.

Because this institution had used both a workshop approach and a course requirement as means by which students were to receive multicultural training, the author was interested in comparing effects of these two approaches. The instrumentation and assumptions used in the 1971 and 1972 studies were employed in this comparative study (5). To determine which approach to multicultural training appeared to be more effective, the study compared the "Workshop" students to the "Required Program" students. The statistical analysis tested the following hypothesis: There would be no difference in the perceptions of ethnic groups held by the workshop students and the required program students.

Gwendolyn Calvert Baker is director, Affirmative Action Programs, and associate professor of education, The University of Michigan, Ann Arbor.
The study was designed to determine the differences in the perceptions of ethnic groups held by students enrolled in two different types of multicultural training programs. 
The data presented in Table 1 show the results of the testing of both the pro-irrational and anti-irrational scales for the total sample. The $t$ value of 1.10 for the pro-irrational scale and the $t$ value of .37 for the antiirrational scale did not reach levels of significance. These findings indicate that there were no significant differences in the perceptions held by these two groups on both scales; the hypothesis was supported.

Further analysis of the subscales indicate no significant difference in the total sample for both groups on either the Black or Minority subscales. The data on the Jewish pro-irrational subscale does indicate change. The mean of 20.41 for Required Program students produced a $t$ of 2.01; the results were significant at the .05 level. These findings indicate that the Required Program students were less pro-irrational in their perceptions of Jewish-Americans than students in the Workshop Program. The move toward less proirrational feelings is a tendency to move towards being rational. It is interesting to note that change occurred on this same subscale in both of the earlier studies; the 1971 study experimentation included a focus on JewishAmericans, while the 1972 study did not.

The total sample was classified into four groups: Rational, Pro-irrational, Anti-irrational, and Confused. The Rational sample on the pro-irrational scale

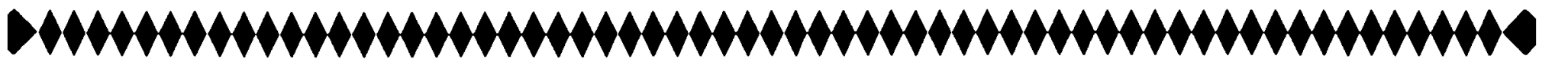

\author{
TABLE 1 \\ SUMMARY OF STUDENTS' T-TESTS FOR WORKSHOP \\ AND REQUIRED PROGRAM' \\ Students' Scores on the "Survey of Groups"
}

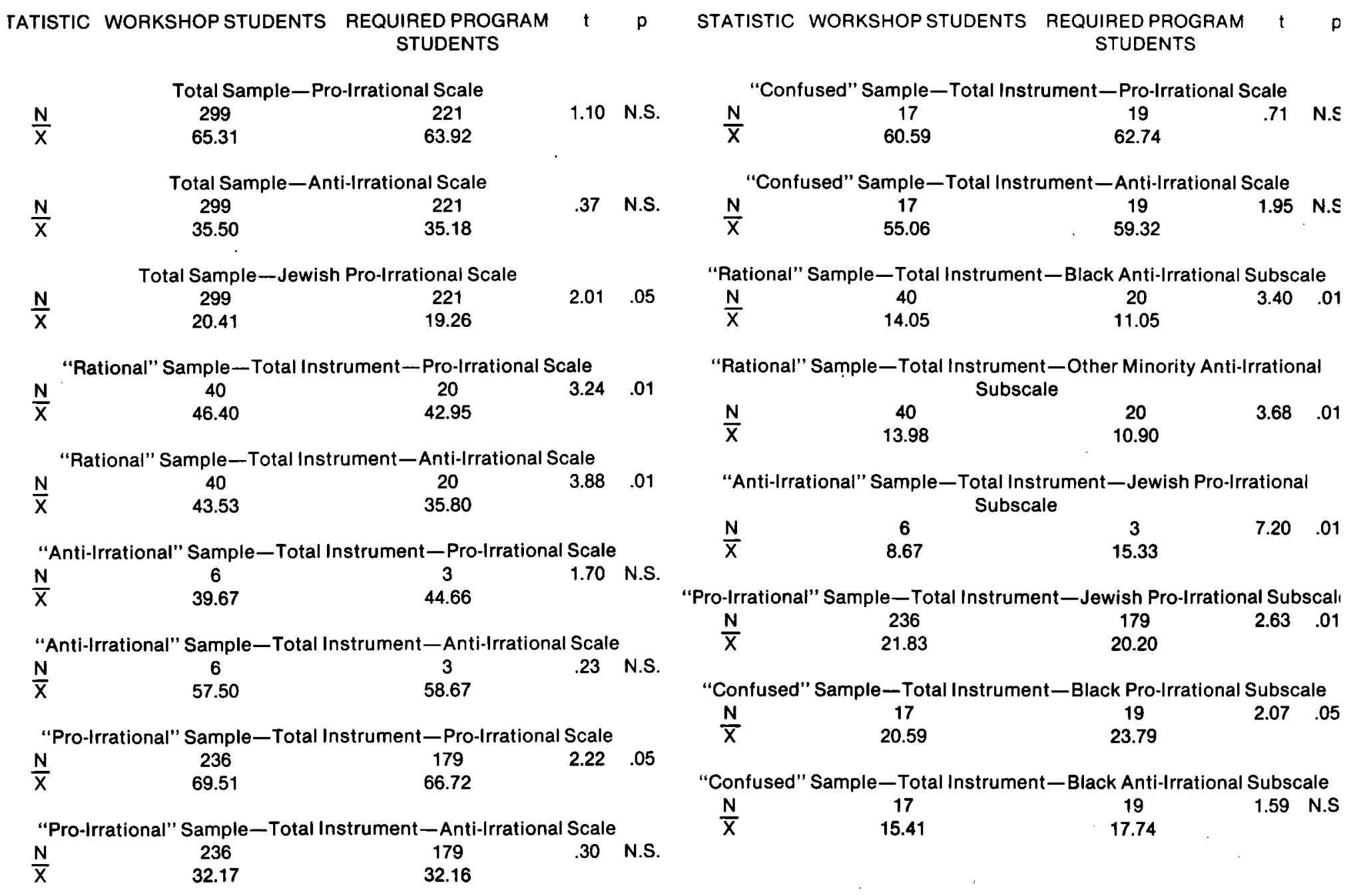

32 Journal of Teacher Education 
produced a $t$ value of 3.24 and was significant at the .01 level. This indicates that the students in the Required Program were less pro-irrational on the total instrument. The mean of $\mathbf{4 3 . 5 3}$ for the 40 "Rational" Workshop students and 35.80 for the 20 Required Program students produced a $t$ of 3.88 and was significant at the .01 level. The results on both of these subscales show the tendency for the Required Program students to be more rational in their perceptions than the Workshop students.

In the analysis of the Anti-irrational, Proirrational, and Confused samples, only the Proirrational sample on the pro-irrational subscale reached a level of significance. The mean of 69.51 for the 236 Workshop students who scored in this category and the mean of 66.72 for the 179 Required Program students produced a $t$ value of 2.22 ; the results were significant at the .05 level. The Required Program students were less pro-irrational on the total instrument pro-irrational scale than the Workshop students were.

The data reported in the remainder of Table 1 show that the Required Program students who were Antiirrational on the total instrument appeared to be more pro-irrational on the Jewish subscale. The same group of students who were classified as Confused also appeared to be more pro-irrational on the Black subscale. The remaining comparisons all indicate that the Required Program students moved more toward being rational in their perceptions than the Workshop group.

\section{Summary}

The study was designed to determine the differences in the perceptions of ethnic groups held by students enrolled in two different types of multicultural training programs. The hypothesis tested was: There would be no difference in the perceptions of ethnic groups held by the Workshop students and the Required Program students.

The data did not establish significant differences between the groups on the total instrument; however, there were significant differences on the subscales as reported. The findings indicate that in all cases reported, except in three instances, the students enrolled in the Required Program were more rational in their perceptions than were the students enrolled in the Workshop. According to the "Survey on Groups" intent, rational tendencies are the desired outcomes.

The findings imply that the students in the longer, more integrated multicultural training program produced the desired responses. Workshops and other less involved approaches to multicultural training have some benefit as indicated by the 1972 study. But when this approach is compared to more comprehensive training, it appears that both time and intensity produce more desirable outcomes.
Multicultural training can affect perceptions of ethnic/cultural groups held by teachers in training. This information encourages teacher training institutions to plan, design, and implement meaningful training in intergroup education. Multicultural education for teachers is crucial if colleges and universities are to be effective institutions through which teachers can be prepared to teach in a culturally diverse nation and world.

Technological, political, economic, and social changes have all contributed to the complexities of our society. Teacher education can prepare individuals to respond to our changing world. Teacher training programs need to be relevant to those issues which will confront us tomorrow. "Unless there is scrupulous selfappraisal, unless every aspect of teacher training is carefully reviewed, the changes initiated in teacher preparation as a result of current crisis will be, like so many changes which have gone before, merely differences which make no difference." (6).

\section{Footnotes}

1 Please note that the author used the term "multiethnic" to describe instruction that primarily focuses on teaching about ethnic groups. "Multicultural" refers to instruction that includes ethnic education but also focuses upon the cultural groups of the United States. This reference provides for the inclusion of religion, sex, and groups relevant to this area of interest.

2 Gwendolyn C. Baker, The Effects of Training in Multiethnic Education on Preservice Teachers' Perceptions of Ethnic Groups, Ph.D. Dissertation, The University of Michigan, 1972.

3 "Multicultural Training for Student Teachers," Journal of Teacher Education 25 (Winter 1973): 307.

4 "Instructional Priorities in a Culturally Pluralistic School," Educational Leadership (December 1974): 176-77.

5 The instrument, "Survey on Groups," designed by Howard Schuman and John Harding was used. It was constructed on the assumption that prejudice involves irrationality.

The scorable content of the instrument can be categorized into the following four groups: Irrational Antis, Irrational Pros, Rationalists, and Confused. The Irrational Antis are those whose responses show choices that are biased against ethnic groups. Those selecting items reflecting bias in favor of ethnic groups are the Irrational Pros. Those respondents showing no irrationality against or in favor of ethnic groups are classified as Rationalists. Those scoring high both in irrationality against and irrationality in favor of the group are considered Confused.

The questionnaire consisted of 48 pairs of generalizations with each item referring to a characteristic of an ethnic group. One third of the items included in the survey dealt with Blacks, referred to as Negroes in the questionnaire; one third dealt with Jews; and one third dealt with a variety of other ethnic groups (American Indians; Puerto Ricans; Japanese-, Chinese-, and Mexican-Americans).

See Howard Schuman and John Harding, "Prejudice and the Norm of Rationality," Sociometry 27 (1964): 35371.

6 B. Othanel Smith, Saul B. Cohen, and Arthur Pearl, Teachers for the Real World (Washington, D.C.: AACTE, 1969), pp. 1-3.

\section{Multicultural training can affect perceptions of ethnic/cultural groups held by teachers in training.}

